
\title{
3 Research Square \\ Local-Scale Damming Impact on the Planktonic Bacterial and Eukaryotic Communities in the Upper Yangtze River
}

\section{Hang Li}

Chongqing Institute of Green and Intelligent Technology

Zhe Li

Chongqing Institute of Green and Intelligent Technology

Qiong Tang

Chongqing Institute of Green and Intelligent Technology

Ran Li

Sichuan University

Lunhui Lu ( $\square$ lulunhui@cigit.ac.cn )

Chongqing Institute of Green and Intelligent Technology

\section{Research Article}

Keywords: Bacteria, Eukaryotes, Keystone species, Local-scale damming impact, the upper Yangtze River

Posted Date: September 21st, 2021

DOI: https://doi.org/10.21203/rs.3.rs-910241/v1

License: (9) This work is licensed under a Creative Commons Attribution 4.0 International License. Read Full License 


\section{Abstract}

Dam construction and reservoir formation alters hydro-morphology of rivers, thereby restructuring microbial communities and biogenic element cycles in river ecosystems. The ecological responses and mechanisms of planktonic communities showed notable changes upstream and downstream of dams. Yet, less is reported about how the ecological mechanisms structuring planktonic communities at the closest area upstream and downstream of dams. In this study, we hypothesized that planktonic communities remained the connectivity or similarities but show distinctive ecological responses to changing environment at the closes area upstream and downstream of dams. Three large dams in the upper Yangtze River were chosen in the study. Field data revealed that the alpha diversity indexes slightly increased downstream of the dams. In addition, more eukaryotic ASVs solely occurred downstream of the dams, indicating that a large proportion of eukaryotes was formed downstream of the dams. Cooccurrence network analysis demonstrated that the keystone species of planktonic bacteria and eukaryotes decreased downstream of the dams, and the modularity increased. The robustness of the cooccurrence relationships among the eukaryotic communities was more strongly influenced by these dams than that among the planktonic bacteria. The variance partitioning analysis results indicated that dam-related variables and local environmental variables mainly shape the assembly of the planktonic microbial communities closest to the dams. In conclusion, dams exert a greater impact on planktonic eukaryotes than on bacteria in near-dam areas, and planktonic bacteria can better adapt to changing environments. Our study provides a better understanding of the ecological effects of river damming.

\section{Introduction}

Currently, many rivers are highly regulated for hydropower or water supply purposes, which generates major hydrological disturbances at the spatial scale [1]. The river continuum concept (RCC) proposed by Vannote et al. [2] considered that biological communities can be characterized as establishing a temporal continuum of synchronized species replacements, and the physical variables within a stream system exhibit a continuous gradient. However, few riverine ecosystems remain free-flowing along their entire course. The serial discontinuity concept (SDC) provides another conceptual framework to describe longitudinal changes in abiotic and biotic variables in rivers under dam influence [3]. Regulation by dams typically results in an alternating series of lentic and lotic reaches, and the disruption in continuous processes and nutrient cycles causes changes in the ecological processes of the entire river [3]. The act of river damming and impounding alters the river continuity, the velocity decreases upon approaching the dam site, and the created reservoir becomes a lacustrine system, thus driving the transition of the aquatic ecosystem from lotic into lentic [4,5]. Moreover, artificial operation of dams for various purposes change the hydraulic retention time and impede the flow of biogenic elements, including carbon, phosphorus, nitrogen and silicon, along with river networks, leading to enhanced biogeochemical cycling [6]. In addition, increased nutrient retention via sedimentation or outgassing in reservoirs influences downstream environments [6]. As a result, the upstream and downstream sections of the reservoirs tend 
to greatly differ in their physical and chemical environments, and the composition and structure of the microbial community correspondingly undergo tremendous changes [1,7-9].

Planktonic bacterial and eukaryotic communities are essential members of aquatic ecosystems with an extremely high level of genetic diversity. Both are important participants in the global biogeochemical cycle $[1,10]$. Planktonic bacteria can assimilate and remineralize inorganic nutrients, which are channeled to higher trophic levels via the predation of protists $[8,11,12]$. The spatial and temporal distributions of microbial processes in freshwater ecosystems may vary depending on environmental variables $[13,14]$, temperature [15], hydrological factors [16, 17], grazing pressure [14], and changes in land use [18], etc., and the microbial diversity and community structure respond to changes in these environmental variables. Planktonic microbial biogeographic patterns and assembly mechanisms have been widely studied in large rivers, such as the River Thames Basin [19], Danube River [20], Mississippi Rivers [21, 22] and Yangtze River [9, 23]. These publications mostly emphasized distance-decay relationships and microbial community changes on a large catchment scale [8]. They considered that dam construction on a river often leads to notable changes in microbial communities at dam-affected sites [7, 24, 25]. In addition, the bacterial taxa in sediments downstream of a dam are drastically reduced due to severe riverbed scouring [9]. Our previous results also found that dams would significantly reduce the a-diversity of planktonic bacterial communities on the large-scale catchment, and the microbial communities/species would be conducive to recovery in river habitats. River damming often causes a sharp rise/decline in physical or hydrological variables, finally causing natural biophysical gradient discontinuities in local environments [3]. However, it remains unclear whether these discontinuities caused by damming would directly or indirectly alter microbial communities and how microbes respond in these local-scale changing habitats. There still remains a knowledge gap regarding the impacts of damming on the transformation of microbial communities downstream of large dams.

At present, correlation network analysis has been widely applied to understand the organization of microbial communities and the interaction between their components in aquatic ecosystems. According to the topological characteristics of the network, potential target species (keystone species) can often be identified at the central node of the network, and these species play a more important role in the network, while their appearance or disappearance can disturb a mature community [26-29]. A particular bacterium in the network may adhere to a particular ecological (or life) strategy [30]. Life strategies represent sets of correlated traits attributed to physiological or evolutionary tradeoffs, and in-plant communities, tradeoffs in key fitness traits have been represented through the conceptual $r$ - and K-selection theories [30-32]. The classification of life strategies has been applied in microbial systems. For example, studies in the Thames River Basin and Lancang-Mekong River Basin indicated that along with the river network from upstream to downstream, the dominant phylum of bacteria shifted from r-strategists (Bacteroidetes) to Kstrategists (Actinobacteria) [19, 25]. In particular, the network interaction and ecological strategies can characterize the response mechanisms of keystone species in these dynamic environments.

It is noteworthy that that large dams are not absolute barriers that disconnect the upstream reservoir and downstream river reach. Waters traveling through dams for hydropower production or other functions will 
bring aquatic microbial community to downstream river reach. Distinctive habitats shape different community assembly mechanisms in the upstream and downstream of the dam, projecting the potential damming impacts on riverine aquatic ecosystems. Compared to the extensive studies on larger scales, we highlighted our study focusing on local scale, i.e. the nearest and most accessible sampling sites upstream and downstream of the dams. We hypothesized that there would be possible links of aquatic microbial community between the sampling sites upstream and downstream of the dam due to the dam operation, shaping the ecological mechanisms of microbial assembly in damming rivers. We tried to explore the different responses of eukaryotic and bacterial communities on such local scale. We believe our study would provide new insights of aquatic microbial ecology in damming rivers.

Here, we selected three large dams in the upper Yangtze River (Xiluodu Dam, Xiangjiaba Dam, and Three Gorges Dam) as the research area. Both 16S rRNA and 18S rRNA high-throughput gene sequencing techniques were applied to investigate the bacterial and eukaryotic communities at sampling sites nearest upstream and downstream of these three dams in May, July, and November 2019. This study aimed to 1) examine the changes in microbial communities and diversity right downstream of these large dams; 2) explore the keystone species and natural connectivity of co-occurrence networks; 3 ) evaluate the potential damming effect on the composition of planktonic bacterial and eukaryotic communities on local scale.

\section{Materials And Methods}

\section{Study area and sample collection}

The upper Yangtze River starts from the Qinghai-Tibet Plateau in the west and ends at Yichang, Hubei in the east. The entire basin covers an area of approximately $1 \mathrm{M} \mathrm{km}^{2}$. The river reach encompasses large drops, rapid currents, many canyons, holding a large economically viable potential of hydropower. At present, the world's largest hydropower plant is built in the upper Yangtze River. The Three Gorges Dam (TGD, with installed capacity of 22500MW), Xiluodu (XLD, 12600MW) Dam and Xiangjiaba (XJB, $6400 \mathrm{MW}$ ) Dam are the selected dams in this study (Fig. 1). The XLD Dam and XJB Dam are two large cascade dams located in the upstream of the Three Gorges Reservoir (TGR). Combined with the Wudongde (10200MW) and Baihetan (16000MW) hydropower stations upstream of the XLD and XJB Dams, the total installed capacity of the four cascade dams is equivalent to twice that of the Three Gorges Reservoirs. These projects focus on power generation, and offer comprehensive benefits such as flood control, shipping and alleviation of the sedimentation problem in the Three Gorges Reservoir [33]. Information on the parameters of the selected dams in this study is listed in Table S1.

These dams exert a profound impact on the aquatic microbial community structure in the upper Yangtze River. To investigate the impact of these dams on the planktonic bacterial and eukaryotic communities, field sampling work were carried out in May, July and November 2019 at the most accessible sampling sites right upstream and downstream of the XLD, XJB and the TGD. Five vertical layers at different depths were sampled upstream of the dams, and one surface water sample downstream of the dams was 
collected at the selected sampling sites. Each sample was obtained at the main channel. A total of 54 samples were obtained, including 45 samples upstream of the dams and 9 samples downstream of the dams. Sample information is provided in Table S2.

A total of $5 \mathrm{~L}$ of water was collected in a clear polypropylene container at each site, which was thoroughly mixed in a bucket and immediately transported at a low temperature ranging from $0 \sim 4^{\circ} \mathrm{C}$. The water samples were then subsampled for DNA-based analysis and physiochemical measurement. A total of $800 \mathrm{~mL}$ water was filtered through membrane filters with a $0.22-\mu \mathrm{m}$ pore size (Millipore, Bedford, MA) to capture microbial cells. Thereafter, the obtained membrane filters were kept frozen at $-86^{\circ} \mathrm{C}$ until DNA extraction.

\section{Physicochemical analysis of the samples}

The water temperature ( $\mathrm{T}$ ), dissolved oxygen (DO), $\mathrm{pH}$, and conductivity along the vertical profile were measured in situ with a multiparameter water quality analyzer (YSI-EXO2, USA). The on-site relative humidity was measured with a hygrometer. Chlorophyll a (Chl-a) was extracted with a Whatman GF/C filter over $24 \mathrm{~h}$ and $90 \%$ acetone, centrifuged at 3,000 rpm for $10 \mathrm{~min}$, and then spectrophotometrically quantified. Dissolved organic carbon (DOC) was filtered with a What man GF/F glass fiber filter membrane and dried at $450^{\circ} \mathrm{C}$ for $4 \mathrm{~h}$, and the filtrate was analyzed and determined with a Vario TOC Cube analyzer (Elemen-tar, Hanau, Germany). Total nitrogen (TN), ammonium nitrogen $\left(\mathrm{NH}_{4}{ }^{+}-\mathrm{N}\right)$, nitrate nitrogen $\left(\mathrm{NO}_{3}{ }^{-}-\mathrm{N}\right)$, nitrite nitrogen $\left(\mathrm{NO}_{2}{ }^{-}-\mathrm{N}\right)$, total phosphorus (TP), dissolved total nitrogen (DTN), and dissolved total phosphorus (DTP) were measured with a UV spectrophotometer. The $\mathrm{CH}_{4}$ and $\mathrm{CO}_{2}$ concentrations in water were determined via the headspace equilibrium method and gas chromatography [34].

\section{DNA extraction, PCR amplification, and Illumina sequencing}

Genomic DNA was extracted from the $0.22-\mu \mathrm{m}$ filters with a PowerWater ${ }^{\circledR}$ DNA Extraction kit (Mo Bio, CA, USA) according to the manufacturer's instructions. PCR and sequencing experiments were performed on combined duplicate DNA extracts. The V3-V4 region of the bacterial 16S rRNA gene was amplified with primer pair 338F (5'-ACTCCTACGGGAGGCAGCAG-3') and 806R (5'-GGACTACCAGGGTATCTAAT-3') [35]. The $V 4$ region of the eukaryotic $18 \mathrm{~S}$ rRNA gene was amplified with universal eukaryotic primers TAReuk454FWD1 (5'-CCAGCASCYGCGGTAATTCC-3') and TAReukREV3 (5'-ACTTTCGTTCT TGATYRA-3') [36]. Amplicons were gel purified with the AxyPrep DNA Gel Extraction Kit (Axygen Biosciences, CA, USA) according to manufacturer instructions and quantified with a QuantiFluor ${ }^{\text {TM }}$-ST (Promega, USA). PCRs were performed in triplicate in a $20 \mu \mathrm{L}$ mixture, which consisted of $4 \mu \mathrm{L} 5 \times$ FastPfu Buffer, $2 \mu \mathrm{L} 2.5 \mathrm{mM}$ dNTPs, $0.8 \mu \mathrm{L}$ primer pairs $(5 \mu \mathrm{M}), 0.4 \mu \mathrm{L}$ FastPfu polymerase, and $10 \mathrm{ng}$ template DNA. Purified amplicons were pooled in equimolar amounts and paired-end sequenced on an Illumina MiSeq platform at the Majorbio Bio-Pharm Technology Co., Ltd., Shanghai, China (http://www.majorbio.com).

\section{Bioinformatics analysis of the sequences}


The remaining sequences were quality filtered and chimeras were identified and filtered with the QIIME 2 pipeline (version 2) [37]. All bioinformatics analyses were based on amplicon sequence variants (ASVs) [38]. Individual ASVs were taxonomically classified with a 99\% identity threshold via the open-reference method (VSEARCH) based on the 16S rRNA genes of kefir isolates as a reference [39]. The taxonomies of nonkefir isolate ASVs were subsequently assigned via comparison to the SILVA 138/16S_bacteria database and the SILVA 138/18S_eukaryota database using BLAST under default settings [40].

Surface water was collected for network analysis to reveal the co-occurrence pattern of the planktonic bacterial and eukaryotic communities. To reduce the complexity of correlation matrix generation, only the ASVs occurring in all samples with $\geq 50$ sequences were retained for the planktonic bacteria, while the ASVs containing $\geq 20$ sequences were retained for the planktonic eukaryotes. To visualize the associations in the networks, the possible pairwise Spearman rank correlation matrix based on the ASV level was calculated with the igraph package in RStudio. Only high Spearman's correlation coefficients $(|r|>0.8)$ and statistically significant $(p<0.05)$ correlations were accepted for network analysis. Gephi software (version 0.9.2) was employed to visualize the network and calculate the overall topological characteristics (the number of nodes, edges, degree, betweenness centrality, modularity, etc.). The node size was determined according to the degree (the number of edges connected to each node) in the network, and the color of the edge was related to the correlation (the pink and green lines indicated positive and negative correlations, respectively). The harbored keystone taxa of microbial communities drive the community composition and function [41]. Keystone species were identified based on the same topological features of the co-occurrence networks, which exhibit a high mean degree, closeness centrality, high transitivity, and betweenness [42]. In this study, nodes with degree (>40) and betweenness centrality $(<1000)$ were selected as the keystone species. The natural connectivity of a complex network was applied to reveal the robustness of the different microbial association networks to random node removal ("attack") [43-45].

\section{Statistical analysis}

Alpha diversity indexes (Sobs, ACE, Shannon, etc.) and dissimilarity-related calculations of the planktonic bacterial and eukaryotic communities in all samples were calculated in RStudio using the vegan package. The Shannon diversity index upstream and downstream of the dams was visualized with a boxplot (Origin 2018). To examine the difference in microbial diversity between the different dams from upstream to downstream, a one-way analysis of variance (ANOVA) was performed in SPSS Statistics 23.0 (IBM). Nonmetric multidimensional scaling analysis (NMDS) based on the Bray-Curtis distance was adopted to visualize the dissimilarity in the planktonic bacterial and eukaryotic communities among the samples (beta diversity). Based on the Bray-Curtis dissimilarity in the species considering 999 permutations, analysis of similarity (ANOSIM) statistics were generated to detect the significant differences in the microbial communities between upstream and downstream dam areas and between reservoirs. A stacked histogram of the species composition was analyzed in Rstudio. To determine the differences in the composition of the planktonic bacterial and eukaryotic ASVs upstream and downstream of the dams, a fan chart of the percentage of upstream_s, coexisting, and downstream_s species was generated based 
on ASV-level Venn diagram results. The linear relationships between various environmental factors and the abundance of keystone species were analyzed via Pearson correlation analysis in R v4.0.3. Moreover, variation partitioning analysis (VPA) was performed to evaluate the relative contribution of the nutrient variables, dam-related variables, and local environmental variables in shaping the microbial communities. Variance inflation factor analysis (VIF) was employed to screen the relevant variables, and those factors with low collinearity were retained for the subsequent analysis (VIF $\leq 10)$. Venn diagram, NMDS, and VIF results, ANOSIM statistics, and Wilcoxon rank-sum test, and Kruskal-Wallis $\mathrm{H}$ test results were visualized and calculated on the online Majorbio cloud platform online (http://www.majorbio.com).

\section{Nucleotide sequence accession numbers}

All raw sequence data generated in this study were deposited in the National Center for Biotechnology Information (NCBI) Sequence Read Archive database (SRA) under the BioProject accession number PRJNA738555 (http://www.ncbi.nlm.nih.gov/sra/).

\section{Results}

\section{Environmental variables of the selected samples under reservoir operation}

The environmental variables of the water samples are listed in Table S3. The water temperature $(T)$ ranged from 13.5 to $27.0^{\circ} \mathrm{C}$. In addition, the $\mathrm{pH}$ values ranged from 7.67 to 9.01 . Moreover, the $\mathrm{T}$ and $\mathrm{pH}$ values in May and July indicated an overall downward trend of the vertical distribution, but in November, there was no obvious stratification. In the sampled surface water, except for the XJB Dam and TGD in November, the concentration of Chl-a decreased from upstream to downstream of the dam. In addition, the TGD exhibited the highest average DOC concentration, while the average DOC concentrations in the XLD and XJB Dams were similar. The $\mathrm{NO}_{3}{ }^{-}-\mathrm{N}, \mathrm{DTN}, \mathrm{TN}, \mathrm{DTP}$ and TP concentrations in the XLD and XJB Dams were mostly lower than those in the TGD. The $\mathrm{NO}_{2}{ }^{-}{ }^{-} \mathrm{N}$ concentration ranged from 0.002 to 0.011 $\mathrm{mg} / \mathrm{L}$ and was lower in the XJB Dam (average: $0.002 \mathrm{mg} / \mathrm{L}$ ) and TGD (average: $0.003 \mathrm{mg} / \mathrm{L}$ ) than that in the XLD Dam (average: $0.005 \mathrm{mg} / \mathrm{L}$ ). The $\mathrm{NH}_{4}{ }^{+}-\mathrm{N}$ concentration ranged from 0.007 to $0.297 \mathrm{mg} / \mathrm{L}$, which was higher in the XJB Dam and TGD and reached its peak before the TGD in November. The $\mathrm{CH}_{4}$ and $\mathrm{CO}_{2}$ concentrations exhibited a gradually increasing trend along the river, and the average concentrations in the TGD reached $3.136 \mathrm{ppm}$ and $1017.489 \mathrm{ppm}$, respectively.

\section{Microbial taxonomic composition, distribution, and alpha diversity analysis}

Total amounts of 1152360 and 1399140 sequences and 4054 and 2985 ASVs were detected for the planktonic bacteria and eukaryotes, respectively. The taxonomic composition and distribution of the planktonic bacterial and eukaryotic communities are shown in Fig. 2a and b. The abundant bacterial phyla inclued Actinobacteria (32.3\%), Proteobacteria (29.1\%), Cyanobacteria (13.2\%), Bacteroidetes 
(11.6\%), Acidobacteria (4.2\%), Planctomycetes (2.4\%) and Chloroflexi (1.6\%), which contributed more than $90 \%$ to all the communities. Generally, there was no significant change in the taxonomic composition of the planktonic bacterial community. However, the relative abundances of Actinobacteria and Acidobacteria increased downstream of the dam, while Proteobacteria and Bacteroidetes revealed the opposite patterns (Fig. 2a). The eukaryotes mainly comprised protozoans, metazoans, and fungi. The metazoans were dominated by Bilateria (31.8\%, including Arthropoda, Rotifera, Nematoda, etc.), the protozoans were dominated by Stramenopiles (29.6\%, including Bacillariophyceae and Chrysophyceae, etc.) and Alveolata (12.3\%, mainly dominated by Ciliophora), and among the other eukaryotic communities, Cryptophyceae is dominated (7.8\%). The changes in the eukaryotic communities were more obvious. The relative abundance of Cryptophyceae significantly increased downstream of the XLD Dam, and Alveolata significantly increased downstream of the TGD, while Bilateria significantly decreased (Fig. 2b). In addition, the ASVs were classified into upstream of the dams solely (upstream_s) species, downstream of the dams solely (downstream_s) species, and coexisting species upstream and downstream of dams (coexisting) (Fig. 2c). In the planktonic bacterial communities, more than half of the ASVs (50.04\%) coexisted upstream and downstream of the dams. However, the percentage of the ASVs coexisting in the eukaryotic communities was lower than that in the planktonic bacterial communities. Most eukaryotic ASVs solely existed after the dams (40.00\%), indicating that the new eukaryotic species were formed downstream of dams (Fig. 2c).

The richness and diversity were assessed based on ASV analysis by calculating the Sobs and Shannon indexes. The alpha diversity indexes of both the planktonic bacterial and eukaryotic communities exhibited an increasing trend downstream of the dams, but there were no significant differences between the upstream and downstream dam sites (Fig. 3a, b, d, and e). In addition, the richness of the microbial communities among the three dams was compared, and the Sobs richness index of the planktonic bacterial and eukaryotic communities in the TGD was significantly higher than that in the XLD and XJB Dams (Fig. 3c and f).

\section{Beta diversity of the planktonic microbial communities upstream and downstream of the dams}

The NMDS results based on the Bray-Curtis distance indicated that there was no obvious geographic clustering of the planktonic bacterial and eukaryotic communities between the different locations (upstream and downstream of the dams) and between the different dams (Fig. 4a and b). In addition, analysis of the similarity between the groups (ANOSIM) confirmed that there were no significant differences in the microbial communities upstream and downstream of the different dams (bacteria: $r=$ $0.209, p=0.001$; eukaryotes: $r=0.076, p=0.042$ ). This phenomenon indicated that the communities were similar upstream and downstream of the dams. Moreover, vertical distance decay relationships were estimated for the microbial communities upstream of dams (five layers). The vertical distance decay relationships significantly increased with increasing vertical distance (Fig. S1). 


\section{Co-occurrence networks of the microbial communities upstream and downstream of the dams}

Only the surface water samples were analyzed to perform co-occurrence network analysis upstream and downstream of the dams. The topological parameters of the bacterial and eukaryotic community cooccurrence networks upstream and downstream of the dams are listed in Table 1. Notably, Fig. 5 shows that most topological parameters (the modularity, nodes, and average path length) increased downstream of the dams. From upstream to downstream of the dams, the modularity of the planktonic bacterial networks was higher than that of the eukaryotic communities. The number of positive edges was larger than that of negative edges, especially in the eukaryotic community network $(96.98 \%$ and $95.36 \%$ positive edges upstream and downstream of the dams, respectively). The community networks in the surface water samples exhibited no significant changes downstream of the dams. There were significant differences in the node-level topological features (closeness centrality, betweenness centrality, and Eigen centrality) between the planktonic bacterial and eukaryotic communities (Fig. S2). In addition, the robustness analysis results indicated that the natural connectivity of the microbial network downstream of the dams decreased faster than did the connectivity upstream of the dam (Fig. 5e and f). There was a significant difference in the stability of the network of the planktonic eukaryotic community $(p<0.001)$ upstream and downstream of the dams, indicating that the network upstream of the dam was more fragile.

Table 1

Topological parameters of the bacterial and eukaryotic community co-occurrence networks.

\begin{tabular}{|lllll|}
\hline & \multicolumn{2}{l}{ Planktonic bacteria } & \multicolumn{2}{l|}{ Planktonic eukaryotes } \\
\cline { 2 - 5 } & $\begin{array}{l}\text { upstream of } \\
\text { the dam }\end{array}$ & $\begin{array}{l}\text { downstream of } \\
\text { the dam }\end{array}$ & $\begin{array}{l}\text { upstream of } \\
\text { the dam }\end{array}$ & $\begin{array}{l}\text { downstream of } \\
\text { the dam }\end{array}$ \\
\hline Nodes & 430 & 462 & 404 & 542 \\
\hline Edges & 3914 & 3793 & 3344 & 4250 \\
\hline Positive edges & $66.07 \%$ & $65.52 \%$ & $96.98 \%$ & $95.36 \%$ \\
\hline Negative edges & $33.93 \%$ & $34.48 \%$ & $3.02 \%$ & $4.64 \%$ \\
\hline Network diameter & 9 & 10 & 11 & 11 \\
\hline Average degree & 18.205 & 16.42 & 16.554 & 15.683 \\
\hline $\begin{array}{l}\text { Average clustering } \\
\text { coefficient }\end{array}$ & 0.491 & 0.505 & 0.768 & 0.669 \\
\hline Graph density & 0.042 & 0.036 & 0.041 & 0.029 \\
\hline Average path length & 3.334 & 3.453 & 3.947 & 4.114 \\
\hline Modularity & 1.384 & 1.669 & 0.846 & 0.863 \\
\hline
\end{tabular}


In the planktonic bacterial communities, a total of 49 ASVs was identified as keystone species, and the main taxa belonged to Proteobacteria (21 ASVs), Cyanobacteria (9 ASVs), Acidobacteria (4 ASVs), and Planctomycetes (4 ASVs). A total of 16 ASVs was identified as keystone species in the eukaryotic community networks, which were predominantly affiliated with Stramenopiles (7 ASVs), Alveolata (3 ASVs), and Choanoflagellata (3 ASVs). The keystone species of the bacterial community decreased downstream of dams, and the keystone species of the eukaryotic communities even disappeared, indicating that the eukaryotes were greatly affected by the dams. In addition, the relative abundance of the keystone species was generally higher in November, which may be related to environmental conditions (Fig. 6).

\section{Effects of dam-related and local environmental variables on the microbial communities}

After VIF analysis, thirteen variables including T, pH, depth, $\mathrm{POM}, \mathrm{TOM}, \mathrm{DOC}, \mathrm{NO}_{2}{ }^{-}-\mathrm{N}, \mathrm{NH}_{4}{ }^{+}-\mathrm{N}, \mathrm{TN}, \mathrm{TP}, \mathrm{CH}_{4}$, maximum dam height, and water level were selected for RDA or CCA. T, pH, DOC, $\mathrm{NO}_{2}{ }^{-}-\mathrm{N}, \mathrm{TN}^{-} \mathrm{CH}_{4}$, maximum dam height, and water level were important variables shaping the planktonic bacterial community composition based on the RDA (Fig. S3, Table S4), while T, POM, TOM, DOC, TN, TP, $\mathrm{CH}_{4}$, and water level were the significant variables of the eukaryotic community composition (Fig. S3, Table S4). In particular, DOC and water level have significant effects on both the planktonic bacterial and eukaryotic communities $(p=0.001)$. The important variables were divided into two groups (dam-related variables and local environmental variables). The VPA results showed that the local environmental variables were the most important factors driving the microbial community assembly. They explained $24.3 \%$ and $22.5 \%$ of the variation in the planktonic bacterial and eukaryotic communities, respectively (Fig. 7). However, $68.4 \%$ and $67.8 \%$, respectively, of the variation remained unexplained.

\section{Discussion}

The well-known RCC describes the riverine physical variables of the natural river system (including width, depth, speed, etc.) under a continuous gradient of conditions, and the response of biotic communities can who can rapidly adapt to such gradients changes in the environment [2]. Yet, when concerning to damming rivers, SDC serves as conceptual basis of discontinuities within the river continuum [46]. Such disturbances structured reciprocal conceptual model of abiotic environmental variables caused by damming and biophysical properties that inherently hold by microbial assemblages. Here, we extended the discussion of our findings in the research into the following three aspects:

\section{Possible connectivity of microbial communities between upstream and downstream dam areas}

Dams are not absolute barriers that disconnect upstream and downstream sampling sites. Indeed, we found similarities or even possible connections of microbial communities between the upstream and 
downstream sampling sites. The beta diversity of both planktonic bacterial and eukaryotic communities based on the Bray-Curtis dissimilarity matrix indicated that the differences of microbial communities between upstream and downstream sampling sites are not apparent (Fig. 4). Such possible differences among the three dams were also not identifiable.

In addition, it was noted that coexisting ASVs in the planktonic bacterial and eukaryotic communities and accounted for a large proportion (Fig. 2c). Among these coexisting species, the top 10 ASVs at the different dams were selected for clustering at the genus level (Fig. S5). The results demonstrated that the dominant genera shared by the three dams were CL500-29_marine_group, hgcl_clade, and norank_f_Vicinamibacteraceae. The first two genera belonged to Actinobacteria, and the latter genus belonged to Acidobacteria. Actinobacteria is typical riverine planktonic bacteria [47, 48], mainly following free-living lifestyles, and they may not be easily affected by particle sinking-induced species loss in rivers $[24,49]$. Cyanobium_PCC-6307 (belonging to Cyanobacteria) attained a higher relative abundance in the XLD and XJB Dams, while this organism was not dominant in the TGD, which may be related to the operating conditions of the reservoir. Among the eukaryotic communities, Mediophyceae (belonging to Stramenopiles) and Arthropoda (belonging to Bilateria) were dominant, both of which are also common eukaryotes in freshwater ecosystems [29, 50, 51].

\section{Local environmental variables structured microbial communities}

The establishment of dams shifts the environment from lotic to lentic, thereby affecting the water quality, and cascade dams may also exert an impact on the local microbial community due to their cumulative effect $[52,53]$. The environmental heterogeneity caused by dam construction may largely affect the composition of the microbial community [24, 52]. We found that local environmental variables directly (Table S4). T, TPM, DOC, TP, and water level were the most significant factors of the eukaryotic

communities, and $\mathrm{DOC}, \mathrm{NO}_{2}{ }^{-}-\mathrm{N}, \mathrm{TN}, \mathrm{CH}_{4}$, and water level were the most significant factors of the bacterial communities (Fig. S3, Table S4). The reduced velocity caused by dam construction promotes the sinking and sedimentation of particulates, which further leads to significant changes in the suspended particle content and composition in river waters [54], and the changes in the particulate content influence the proportion of microorganisms [11]. The reduction in the concentration of suspended particles also leads to a reduction in the electrical conductivity and DOC concentration, and the DOC concentration exerts a significant impact on the microbial community. The VPA results further support the above findings. Consistent with the results of most previous studies $[8,25,55]$, the local environmental variables played a dominant role in community assembly (Fig. 7), and which could explain more of the variation in the bacterial communities.

Moreover, some research reported that the alpha diversity of planktonic bacteria decreased from upstream to downstream $[20,24]$. One explanation of this result is that the planktonic bacteria from thereon towards river mouths are affected by process of external input and mass effects [20], and the other is that changes in water chemistry properties lead to changes in bacterial communities through a 
process of species sorting [24]. In this larger-scale study, the decreasing importance of the "riparian influence" leads to a reduction in the alpha diversity of planktonic eukaryotes with the river continuum [8]. Yet, in our study, we did not find such phenomenon (Fig. 3a, b, d, and e). It can simply be justified as follows: first, the distinctive habitat between the upstream and downstream sampling sites. Our research only focuses on dams at the local scale (a range of several kilometers or no more than ten kilometers), which different from the most previous studies. Under the background of this local scale, the barrier of the dam has caused the difference in the habitat conditions of the upstream and downstream of the dam areas; Second, different habitats form unique local environmental variables. Changes in variables such as the $\mathrm{pH}, \mathrm{DO}$, and nutrient variables may increase the adaptability of microorganisms to the environment, leading to an increase in microbial diversity within a small area. In summary, the impact of river damming on the microbial community structure requires further research.

\section{Different eco-physiological responses of eukaryotic and bacterial communities}

Planktonic bacteria and eukaryotes are different groups with different eco-physiological adaptive mechanisms. In general, planktonic bacteria can adapt well to fast changing environments, e.g. lotic system, as a result of their small size and rapid growth rates [56]. In our study, Actinobacteria accounted for a large proportion both upstream and downstream of the dams (Fig. 2a). Actinobacteria represent various ecotypes or exhibit a pronounced ecophysiological plasticity [57]. Certain aquatic Actinobacteria are better protected from protestant grazing than are other heterotrophic planktonic bacteria due to their relatively small cell size and specific cell wall structure $[58,59]$. Changes in the taxonomic composition of the planktonic eukaryotic communities were more affected by the dams, especially Alveolata, which significantly increased downstream of the TGD (Fig. 2b). Ciliophora (belonging to Alveolata) is an important consumer of picophytoplankton and bacteria [60], and its biomass is correlated with the dynamics of phytoplankton blooms [26].

Response of keystone species projected the eco-physiological differences between planktonic bacterial and eukaryotic communities. The relative abundance of the keystone species was generally high in November (Fig. 6). November is the storage period of the reservoir [61]. The rise in water level and the increase in hydraulic residence time alter the living environment of microorganisms and lead to changes in certain species $[11,62]$. The keystone species in the microbial networks did not exhibit significant differences upstream and downstream of the dam (Fig. S6). Yet, they exhibited different survival strategies, caused by their distinctive functional traits, including resource acquisition and utilization traits, constitute the basis for determining the community structure and diversity and defines the diverse ecological strategies selected in different environments [63-65]. Bacteroidetes achieved a higher relative abundance upstream of the dam, while Actinobacteria revealed the opposite trend (Fig. 2a, Fig. S6). It was reported that Bacteroidetes are r-strategists, and their level of competition upstream is lower, which facilitates the growth of this species that can quickly utilize resources $[19,25,66]$. In contrast, Actinobacteria is a K-strategist with an advantage in the intense competition for survival in the downstream, and they tend to attain a lower growth rate and a narrower niche $[19,25,66]$. Actinobacteria 
is also considered a defense strategy against bacteria because of their very small cell morphology, and their increase downstream might indicate an increase in enhanced grazing pressure on downstream bacteria [1].

Rivers are altered from a lotic environment to a semantic or lentic ecosystem because of the interception effect of dams [5]. The survival strategies of microorganisms are almost always the sum of the diverse elementary behavioral reactions to complex and changeable environments, and it is difficult to classify these strategies clearly [30]. Hence, further research on the survival strategies of microbial communities in rivers is needed.

\section{Conclusion}

Microbial communities' connectivity exists in a local area upstream and downstream of the dams. The communities of planktonic bacteria and eukaryotes showed similar trends in the dam areas. Eukaryotic communities are more strongly affected by dams than bacterial communities. Planktonic bacteria could better adapt to changing environments due to their unique eco-physiological characteristics. The network stability of eukaryotic communities was enhanced downstream of the dam, which may be related to the emergence of more new species downstream of the dam. In addition, local environmental variables made a greater contribution to microbial community composition than dam-related variables. The changes in the water environment caused by dam damming have led to changes in the interactions among different species, and the dominant phylum of keystone species in the network have changed from upstream to downstream of the dam areas.

\section{Declarations}

\section{Acknowledgments}

The National Natural Science Foundation of China (Project No. 51861125204 and 52039006) and the Chongqing Bureau of Science and Technology (Project No. cstc2020jscx-msxmX0121, and No. cstc2020jcyj-jqX0010) supported this study. Dr. Lu, and Dr. Li were also supported by the "Light of West" Program funded by the Chinese Academy of Sciences.

We also thank Wei Tan, Qi Zhang, and Xing Chen, who participated in the field sampling campaigns. All the data in the manuscript are accessible and can be requested from the corresponding author.

\section{Author Contributions}

H. Li: Methodology, Writing-original draft. Q. Tang: Review \& editing, Data analysis. R. Li: Methodology, Review \& editing. Z. Li: Conceptualization, Review \& editing, Funding acquisition. L. Lu: Investigation, Experiment, Writing-original draft, Review \& editing.

\section{Declarations}


Ethics Approval Not applicable.

Consent to Participate Not applicable.

Consent for Publication Not applicable.

Competing Interests The authors declare no competing interests.

\section{References}

1. Ruiz-González C, Proia L, Ferrera I, Gasol JM, Sabater S (2013) Effects of large river dam regulation on bacterioplankton community structure. FEMS Microbiol Ecol 84:316-331. https://doi.org/10.1111/1574-6941.12063

2. Vannote RL, Minshall G, Cummins K, Sedell J, Gushing CE (1980) The river continuum concept. Can J Fish Aquat Sci 37:130-137. https://doi.org/10.1139/F80-017

3. Ward JV, Stanford JA (1983) The serial discontinuity concept of lotic ecosystems. In: Fontaine T D, Bartell SM. (eds.). Dynamics of lotic ecosystems. Ann Arbor Scientific Publishers pp. 29-42

4. Winton RS, Calamita E, Wehrli B (2019) Reviews and syntheses: dams, water quality and tropical reservoir stratification. Biogeosciences 16:1657-1671. https://doi.org/10.5194/bg-16-1657-2019

5. Baxter R (1977) Environmental effects of dams and impoundments. Annu Rev Ecol S 8:255-283. https://doi.org/10.1146/annurev.es.08.110177.001351

6. Maavara T, Chen QW, Van Meter K, Brown LE, Zhang JY, Ni JR, Zarfl C (2020) River dam impacts on biogeochemical cycling. Nat Rev Environ Earth 1:103-116. https://doi.org/10.1038/s43017-0190019-0

7. Chen J, Wang PF, Wang C, Wang X, Miao LZ, Liu S, Yuan QS (2018) Bacterial communities in riparian sediments: a large-scale longitudinal distribution pattern and response to dam construction. Front Microbiol 9:999. https://doi.org/10.3389/fmicb.2018.00999

8. Lu LH, Zou X, Yang JX, Xiao Y, Wang YC, Guo JS, Li Z (2020) Biogeography of eukaryotic plankton communities along the upper Yangtze River: the potential impact of cascade dams and reservoirs. $J$ Hydrol 590:125495. https://doi.org/10.1016/j.jhydrol.2020.125495

9. Liu T, Zhang AN, Wang JW, Liu SF, Jiang XT, Dang CY, Ma T, Liu ST, Chen Q, Xie SG, Zhang T, Ni JR (2018) Integrated biogeography of planktonic and sedimentary bacterial communities in the Yangtze River. Microbiome 6:16. https://doi.org/10.1186/s40168-017-0388-x

10. Liu LM, Yang J, Yu Z, Wilkinson DM (2015) The biogeography of abundant and rare bacterioplankton in the lakes and reservoirs of China. ISME J 9:2068-2077. https://doi.org/10.1038/ismej.2015.29

11. Wang PF, Wang X, Wang C, Miao LZ, Hou J, Yuan QS (2017) Shift in bacterioplankton diversity and structure: influence of anthropogenic disturbances along the Yarlung Tsangpo River on the Tibetan Plateau, China. Sci Rep 7:12529. https://doi.org/10.1038/s41598-017-12893-4

12. Newton RJ, Jones SE, Eiler A, McMahon KD, Bertilsson S (2011) A guide to the natural history of freshwater lake bacteria. Microbiol Mol Biol Rev 75:14-49. https://doi.org/10.1128/MMBR.00028-10 
13. Nelson CE, Carlson CA (2011) Differential response of high-elevation planktonic bacterial community structure and metabolism to experimental nutrient enrichment. PLoS ONE 6:e18320. https://doi.org/10.1371/journal.pone.0018320

14. Horňák K, Mašín M, Jezbera J, Bettarel Y, Nedoma J, Sime-Ngando T, Šimek K (2005) Effects of decreased resource availability, protozoan grazing and viral impact on a structure of bacterioplankton assemblage in a canyon-shaped reservoir. FEMS Microbiol Ecol 52:315-327. https://doi.org/10.1016/j.femsec.2004.11.013

15. Xu Y, Guo XJ, Dan Y, Yang ZJ, Ma J, Liu DF, Xu YQ (2021) Impact of cascade reservoirs on continuity of river water temperature: a temperature trend hypothesis in river. Hydrol Process 35:e13994. https://doi.org/10.1002/hyp.13994

16. Yang ML, Shi J, Wang BL, Xiao J, Li WZ, Liu CQ (2020) Control of hydraulic load on bacterioplankton diversity in cascade hydropower reservoirs, southwest China. Microb Ecol 80:537-545. https://doi.org/10.1007/s00248-020-01523-8

17. Lindström ES, Bergström AK (2004) Influence of inlet bacteria on bacterioplankton assemblage composition in lakes of different hydraulic retention time. Limnol Oceanogr 49:125-136. https://doi.org/10.4319/lo.2004.49.1.0125

18. Zhou L, Chen WY, Sun JJ, Liu L, Huang XD (2020) Spatial variation in bacterioplankton communities in the Pearl River, South China: impacts of land use and physicochemical factors. Microorganisms 8:814. https://doi.org/10.3390/microorganisms8060814

19. Read DS, Gweon HS, Bowes MJ, Newbold LK, Field D, Bailey MJ, Griffiths RI (2015) Catchment-scale biogeography of riverine bacterioplankton. ISME J 9:516-526. https://doi.org/10.1038/ismej.2014.166

20. Savio D, Sinclair L, ljaz UZ, Parajka J, Reischer GH, Stadler P, Blaschke AP, Blöschl G, Mach RL, Kirschner AKT, Andreas HF, Alexander E (2015) Bacterial diversity along a 2600 km river continuum. Environ Microbiol 17:4994-5007. https://doi.org/10.1111/1462-2920.12886

21. Payne JT, Millar JJ, Jackson CR, Ochs CA (2017) Patterns of variation in diversity of the Mississippi River microbiome over 1,300 kilometers. PLoS ONE 12:e0174890. https://doi.org/10.1371/journal.pone.0174890

22. Jackson CR, Millar JJ, Payne JT, Ochs CA (2014) Free-living and particle-associated bacterioplankton in large rivers of the Mississippi River basin demonstrate biogeographic patterns. Appl Environ Microbiol 80:7186-7195. https://doi.org/10.1128/aem.01844-14

23. Wang Y, Ye F, Wu SJ, Wu JP, Yan J, Xu KQ, Hong YG (2020) Biogeographic pattern of bacterioplanktonic community and potential function in the Yangtze River: roles of abundant and rare taxa. Sci Total Environ 747:141335. https://doi.org/10.1016/j.scitotenv.2020.141335

24. Chen J, Wang PF, Wang C, Wang X, Miao LZ, Liu S, Yuan QS, Sun SH (2020) Distinct assembly mechanisms underlie similar biogeographic patterns of rare and abundantbacterioplankton in cascade reservoirs of a large river. Front Microbiol 11:158. https://doi.org/10.1111/1462-2920.14993 
25. Wang X, Wang C, Wang PF, Chen J, Miao LZ, Feng T, Yuan QS, Liu S (2018) How bacterioplankton community can go with cascade damming in the highly regulated Lancang-Mekong River Basin. Mol Ecol 27:4444-4458. https://doi.org/10.1111/mec.14870

26. Mikhailov IS, Zakharova YR, Bukin YS, Galachyants YP, Petrova DP, Sakirko MV, Likhoshway YV (2019) Co-occurrence networks among bacteria and microbial eukaryotes of Lake Baikal during a spring phytoplankton bloom. Microb Ecol 77:96-109. https://doi.org/10.1007/s00248-018-1212-2

27. Yang YZ, Gao YC, Huang XN, Ni P, Wu YN, Deng Y, Zhan AB (2019) Adaptive shifts of bacterioplankton communities in response to nitrogen enrichment in a highly polluted river. Environ Pollut 245:290-299. https://doi.org/10.1016/j.envpol.2018.11.002

28. Qin Y, Tang Q, Lu LH, Wang YC, Izaguirre I, Li Z (2021) Changes in planktonic and sediment bacterial communities under the highly regulated dam in the mid-part of the Three Gorges Reservoir. Appl Microbiol Biotechnol 105:839-852. https://doi.org/10.1007/s00253-020-11047-3

29. Yang N, Li Y, Zhang WL, Lin L, Qian B, Wang LF, Niu LH, Zhang HJ (2020) Cascade dam impoundments restrain the trophic transfer efficiencies in benthic microbial food web. Water Res 170:115351. https://doi.org/10.1016/j.watres.2019.115351

30. Golovlev EL (2001) Ecological strategy of bacteria: specific nature of the problem. Microbiology 70:379-383. https://doi.org/10.1023/A:1010476507199

31. Grime JP (1977) Evidence for the existence of three primary strategies in plants and its relevance to ecological and evolutionary theory. Am Nat 111:1169-1194. https://doi.org/10.1086/283244

32. Malik AA, Martiny JBH, Brodie EL, Martiny AC, Treseder KK, Allison SD (2020) Defining trait-based microbial strategies with consequences for soil carbon cycling under climate change. ISME J 14:19. https://doi.org/10.1038/s41396-019-0510-0

33. Zhu LL, Xu QX, Dong BJ, Qin LL (2021) Study on the effect and influencing factors of sand discharge of Xiluodu Reservoir in the Lower Jinsha River. Advances in Water Science (Chinese Edition) 32:544555. https://doi.org/10.14042/j.cnki.32.1309.2021.04.006

34. Qin Y, Zhang YY, Li Z, Ma JR (2018) $\mathrm{CH}_{4}$ fluxes during the algal bloom in the Pengxi River. Environment Science (Chinese Edition) 39:1578-1588. https://doi.org/10.13227/j.hjkx.201706044

35. Huws SA, Edwards JE, Kim EJ, Scollan ND (2007) Specificity and sensitivity of eubacterial primers utilized for molecular profiling of bacteria within complex microbial ecosystems. J Microbiol Methods 70:565-569. https://doi.org/10.1016/j.mimet.2007.06.013

36. Stoeck T, Bass D, Nebel M, Christen R, Jones MDM, Breiner HW, Richards TA (2010) Multiple marker parallel tag environmental DNA sequencing reveals a highly complex eukaryotic community in marine anoxic water. Mol Ecol 19:21-31. https://doi.org/10.1111/j.1365-294X.2009.04480.x

37. Bolyen E, Rideout JR, Dillon MR et al (2019) Reproducible, interactive, scalable and extensible microbiome data science using QIIME 2. Nat Biotechnol 37:852-857. https://doi.org/10.1038/s41587-019-0209-9

38. Callahan BJ, McMurdie PJ, Holmes SP (2017) Exact sequence variants should replace operational taxonomic units in marker-gene data analysis. ISME J 11:2639-2643. 
https://doi.org/10.1038/ismej.2017.119

39. Rognes T, Flouri T, Nichols B, Quince C, Mahé F (2016) VSEARCH: a versatile open source tool for metagenomics. Peer J 4:e2584. https://doi.org/10.7717/peerj.2584

40. Quast C, Pruesse E, Yilmaz P, Gerken J, Schweer T, Yarza P, Peplies J, Glöckner FO (2012) The SILVA ribosomal RNA gene database project: improved data processing and web-based tools. Nucleic Acids Res 41:D590-D596. https://doi.org/10.1093/nar/gks1219

41. Banerjee S, Schlaeppi K, van der Heijden MGA (2018) Keystone taxa as drivers of microbiome structure and functioning. Nat Rev Microbiol 16:567-576. https://doi.org/10.1038/s41579-0180024-1

42. Berry D, Widder S (2014) Deciphering microbial interactions and detecting keystone species with cooccurrence networks. Front Microbiol 5:219. https://doi.org/10.3389/fmicb.2014.00219

43. Wu J, Mauricio B, Tan YJ, Deng HZ (2010) Natural connectivity of complex networks. Chin Phys Lett 27:078902. https://doi.org/10.1088/0256-307x/27/7/078902

44. Albert R, Jeong H, Barabási AL (2000) Error and attack tolerance of complex networks. Nature 406:378-382. https://doi.org/10.1038/35019019

45. lyer S, Killingback T, Sundaram B, Wang Z (2013) Attack robustness and centrality of complex networks. PLoS ONE 8:e59613. https://doi.org/10.1371/journal.pone.0059613

46. Stanford JA, Ward JV (2001) Revisiting the serial discontinuity concept. Regul Rivers Res Manage 17:303-310. https://doi.org/10.1002/rrr.659

47. Portillo MC, Anderson SP, Fierer N (2012) Temporal variability in the diversity and composition of stream bacterioplankton communities. Environ Microbiol 14:2417-2428. https://doi.org/10.1111/j.1462-2920.2012.02785.x

48. Crump BC, Peterson BJ, Raymond PA, Amon RMW, Rinehart A, McClelland JW, Holmes RM (2009) Circumpolar synchrony in big river bacterioplankton. PNAS 106:21208-21212. https://doi.org/10.1073/pnas.0906149106

49. Böckelmann U, Manz W, Neu TR, Szewzyk U (2000) Characterization of the microbial community of lotic organic aggregates ('river snow') in the Elbe River of Germany by cultivation and molecular methods. FEMS Microbiol Ecol 33:157-170. https://doi.org/10.1016/S0168-6496(00)00056-8

50. Gong J, Shi F, Ma B, Dong J, Pachiadaki M, Zhang XL, Edgcomb VP (2015) Depth shapes $\alpha-$ and $\beta-$ diversities of microbial eukaryotes in surficial sediments of coastal ecosystems. Environ Microbiol 17:3722-3737. https://doi.org/10.1111/1462-2920.12763

51. David GM, Moreira D, Reboul G, Annenkova NV, Galindo LJ, Bertolino P, López-Archilla Al, Jardillier L, López-García P (2020) Environmental drivers of plankton protist communities along latitudinal and vertical gradients in the oldest and deepest freshwater lake. Environ Microbiol 23:1436-1451. https://doi.org/10.1111/1462-2920.15346

52. Timpe K, Kaplan D (2017) The changing hydrology of a dammed Amazon. Sci Adv 3:e1700611. https://doi.org/10.1126/sciadv.1700611 
53. Agostinho AA, Pelicice FM, Gomes LC (2008) Dams and the fish fauna of the Neotropical region: impacts and management related to diversity and fisheries. Braz J Biol 68:1119-1132. https://doi.org/10.1590/s1519-69842008000500019

54. Klaver G, van Os B, Negrel P, Petelet-Giraud E (2007) Influence of hydropower dams on the composition of the suspended and riverbank sediments in the Danube. Environ Pollut 148:718-728. https://doi.org/10.1016/j.envpol.2007.01.037

55. Isabwe A, Yang JR, Wang YM, Liu LM, Chen HH, Yang J (2018) Community assembly processes underlying phytoplankton and bacterioplankton across a hydrologic change in a human-impacted river. Sci Total Environ 630:658-667. https://doi.org/10.1016/j.scitotenv.2018.02.210

56. Zeglin LH (2015) Stream microbial diversity in response to environmental changes: review and synthesis of existing research. Front Microbiol 6. https://doi.org/10.3389/fmicb.2015.00454

57. Allgaier M, Brückner S, Jaspers E, Grossart HP (2007) Intra- and inter-lake variability of free-living and particle-associated Actinobacteria communities. Environ Microbiol 9:2728-2741. https://doi.org/10.1111/j.1462-2920.2007.01385.x

58. Pernthaler J, Posch T, Simek K, Vrba J, Pernthaler A, Glöckner FO, Nübel U, Psenner R, Amann R (2001) Predator-specific enrichment of Actinobacteria from a cosmopolitan freshwater clade in mixed continuous culture. Appl Environ Microbiol 67:2145-2155. https://doi.org/10.1128/AEM.67.5.2145-2155.2001

59. Holmfeldt K, Dziallas C, Titelman J, Pohlmann K, Grossart HP, Riemann L (2009) Diversity and abundance of freshwater Actinobacteria along environmental gradients in the brackish northern Baltic Sea. Environ Microbiol 11:2042-2054. https://doi.org/10.1111/j.1462-2920.2009.01925.x

60. Sherr EB, Sherr BF (2002) Significance of predation by protists in aquatic microbial food webs. Antonie Van Leeuwenhoek 81:293-308. https://doi.org/10.1023/A:1020591307260

61. Stanford JA, Ward JV (2001) Revisiting the serial discontinuity concept. Regul Rivers Res Manage 17:303-310. https://doi.org/10.1002/rrr.659

62. Wang JT, Fan HB, He XJ, Zhang FB, Xiao JB, Yan ZL, Feng JJ, Li R (2021) Response of bacterial communities to variation in water quality and physicochemical conditions in a river-reservoir system. Glob Ecol Conserv 27:e01541. https://doi.org/10.1016/j.gecco.2021.e01541

63. Porter SS, Rice KJ (2013) Trade-offs, spatial heterogeneity, and the maintenance of microbial diversity. Evolution 67:599-608. https://doi.org/10.1111/j.1558-5646.2012.01788.x

64. Litchman E, Edwards KF, Klausmeier CA (2015) Microbial resource utilization traits and trade-offs: implications for community structure, functioning, and biogeochemical impacts at present and in the future. Front Microbiol 6. https://doi.org/10.3389/fmicb.2015.00254

65. Kneitel JM, Chase JM (2004) Trade-offs in community ecology: linking spatial scales and species coexistence. Ecol Lett 7:69-80. https://doi.org/10.1046/j.1461-0248.2003.00551.x

66. Weinbauer MG, Höfle MG (1998) Distribution and life strategies of two bacterial populations in a eutrophic lake. Appl Environ Microbiol 64:3776-3783. https://doi.org/10.1128/aem.64.10.37763783.1998 


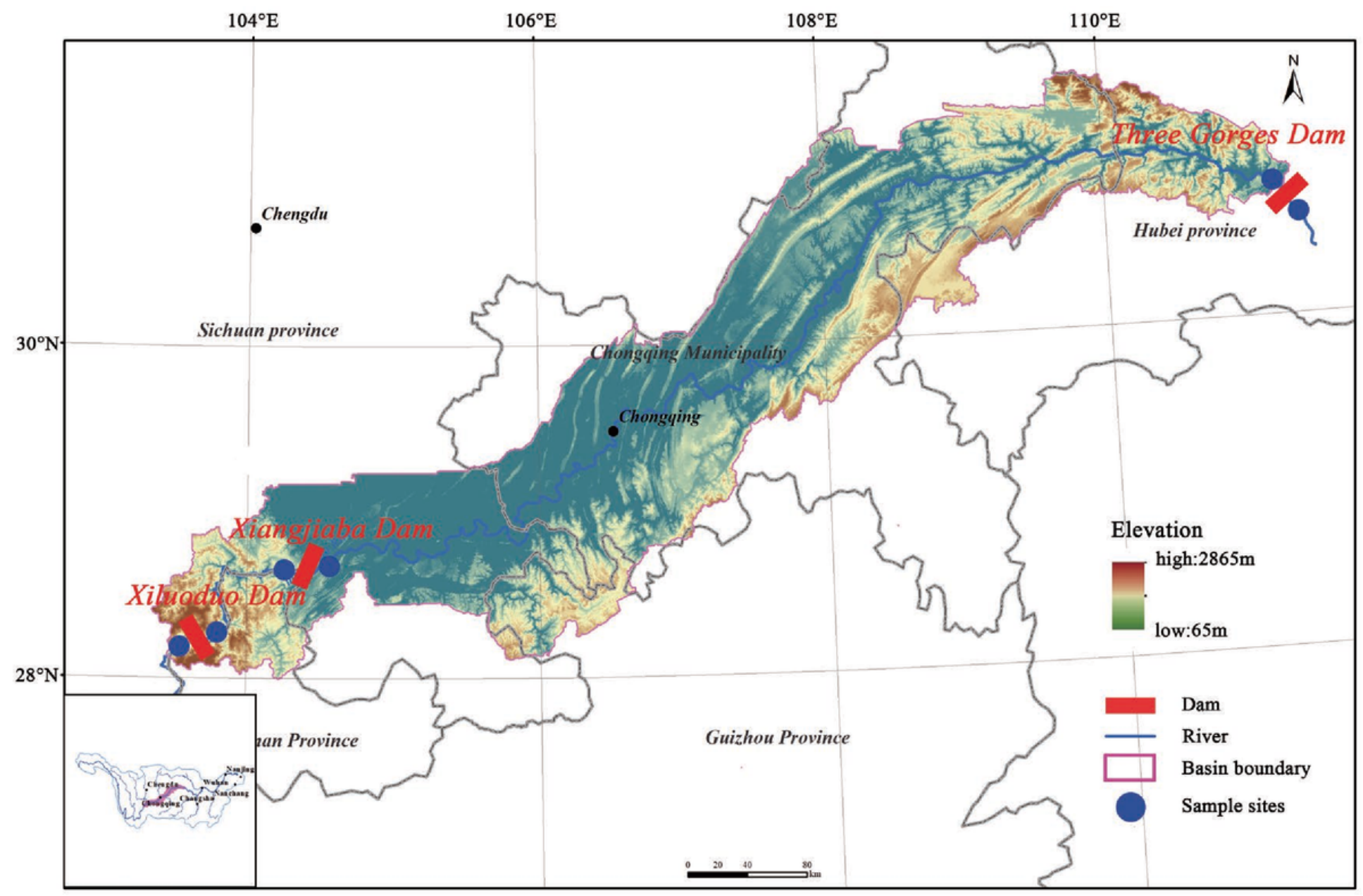

\section{Figure 1}

Maps of the location of the involved dams with the sampling sites. 

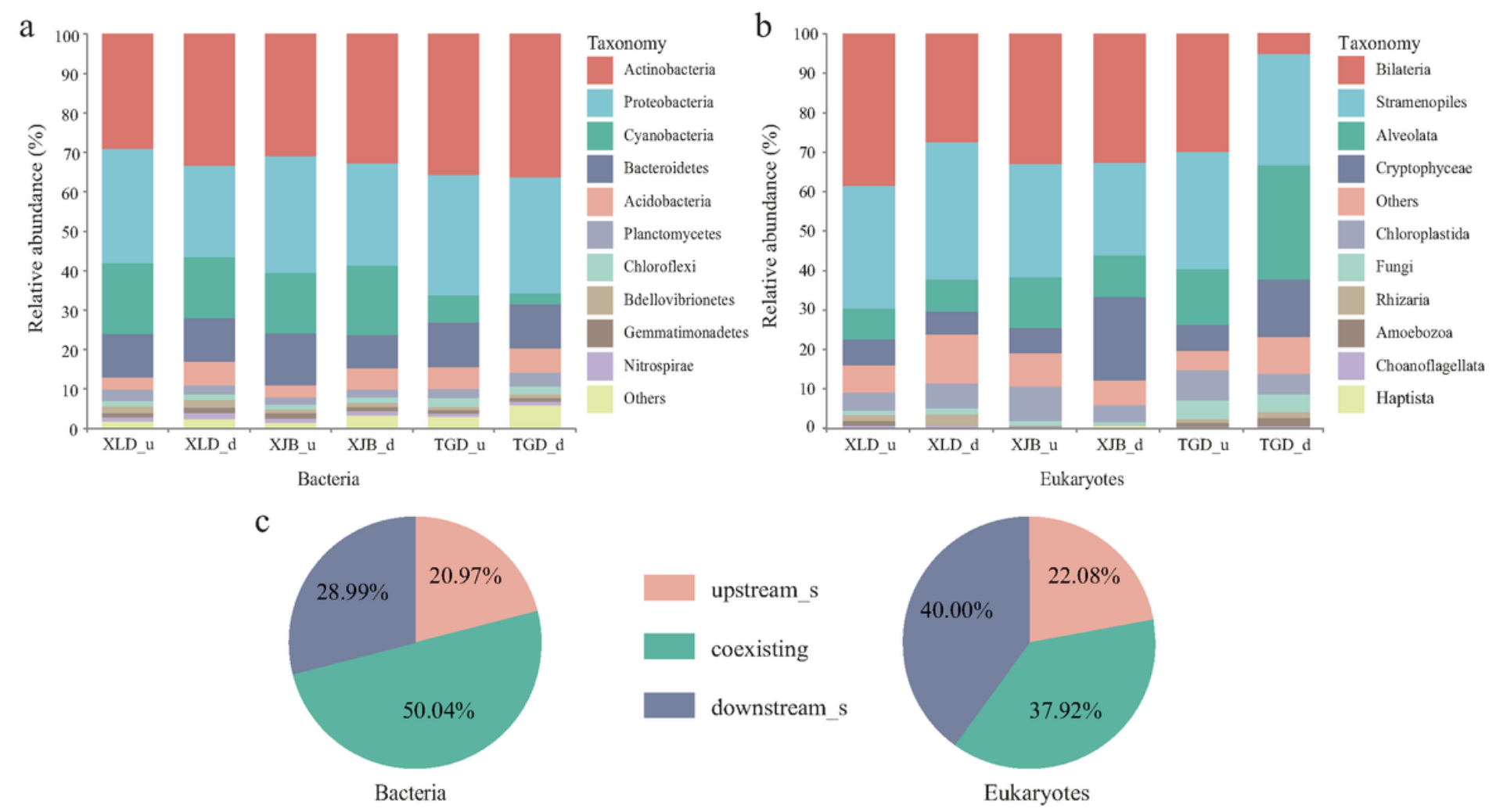

\section{Figure 2}

Taxonomic composition and distribution of the planktonic bacterial and eukaryotic communities. (a) Relative abundance of the bacterial communities at the different sites based on the phylum level; (b) relative abundance of the eukaryotic communities at the different sites based on the taxonomic level; (c) fraction of the different subcommunities (upstream of the dams solely, downstream of the dams solely and coexisting upstream and downstream of the dams) in the planktonic bacterial and eukaryotic communities. XLD_u, upstream of the XLD Dam; XLD_d, downstream of the XLD Dam; XJB_u, upstream of the XJB Dam; XJB_d, downstream of the XLD Dam; TGD_u, upstream of the TGD; TGD_d, downstream of the TGD. The symbols below have the same meaning. 

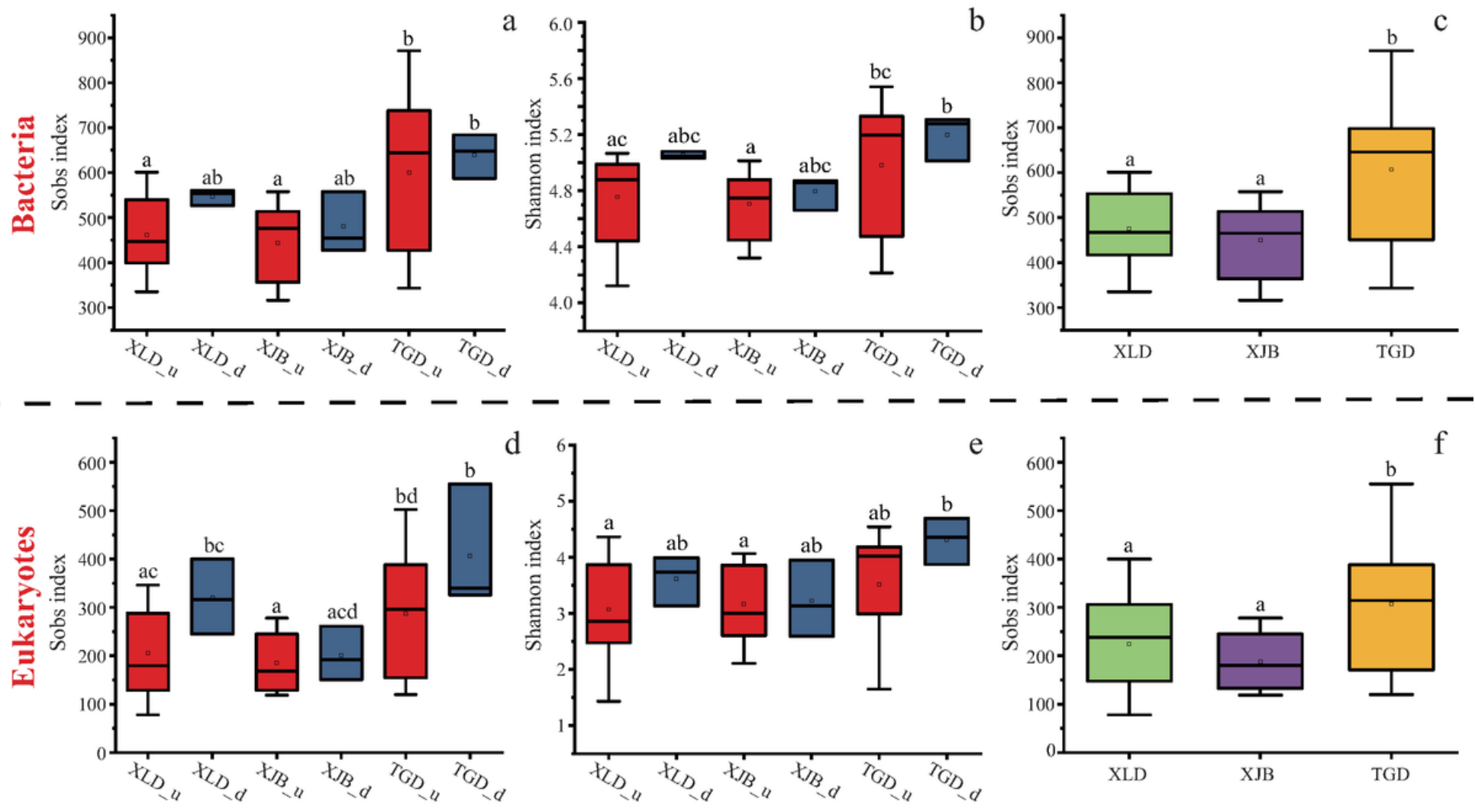

Figure 3

Sobs and Shannon indexes chart of the planktonic bacteria and eukaryotes. The top and bottom boundaries of each box indicate the 75th and 25th quartile values, respectively, and lines within each box represent the median values. The different letters indicate the significance level determined via one-way ANOVA, at $P<0.05$. 

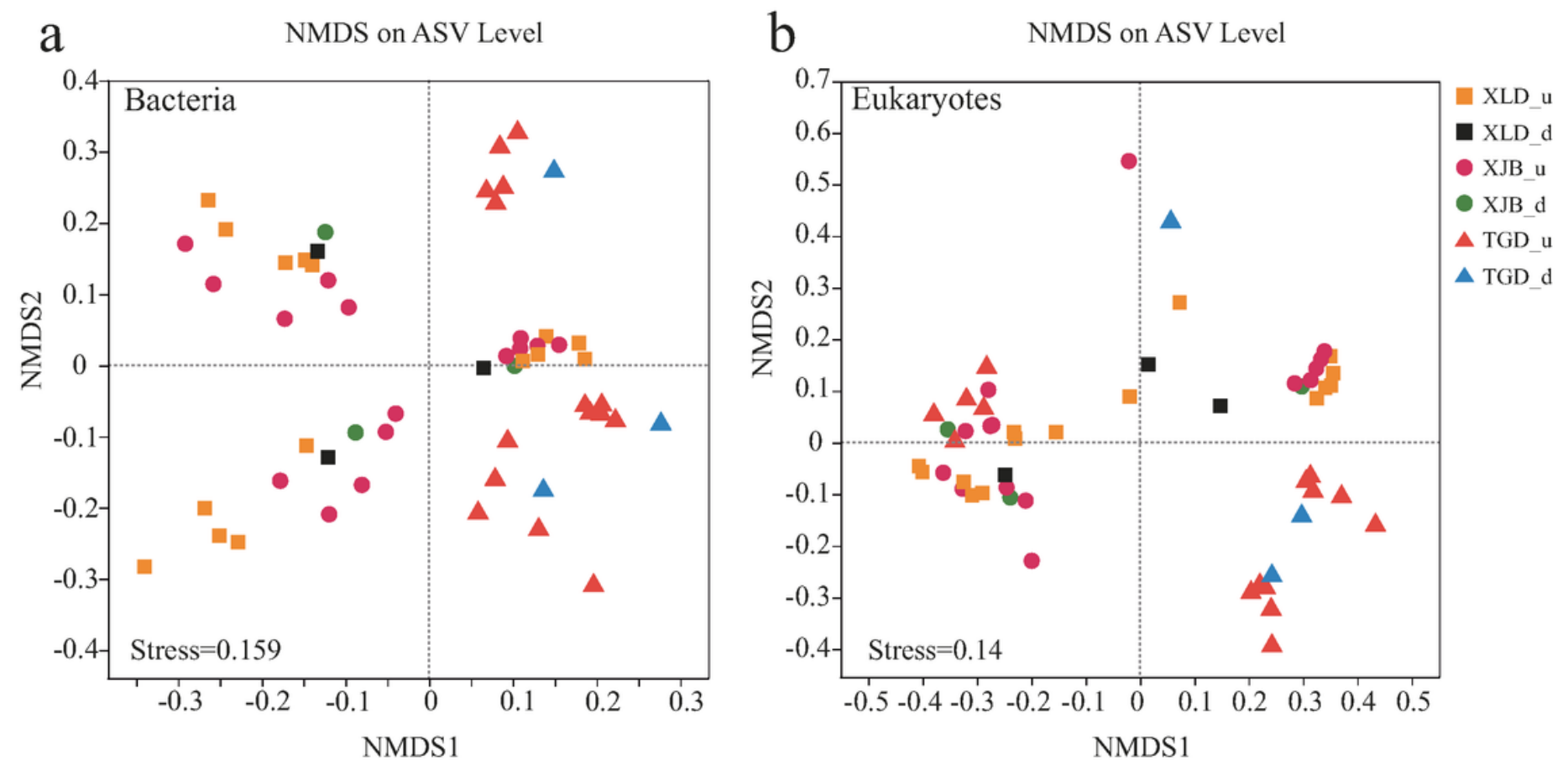

Figure 4

Nonmetric multidimensional scaling (NMDS) analysis of the planktonic bacterial and eukaryotic communities at the ASV level. 

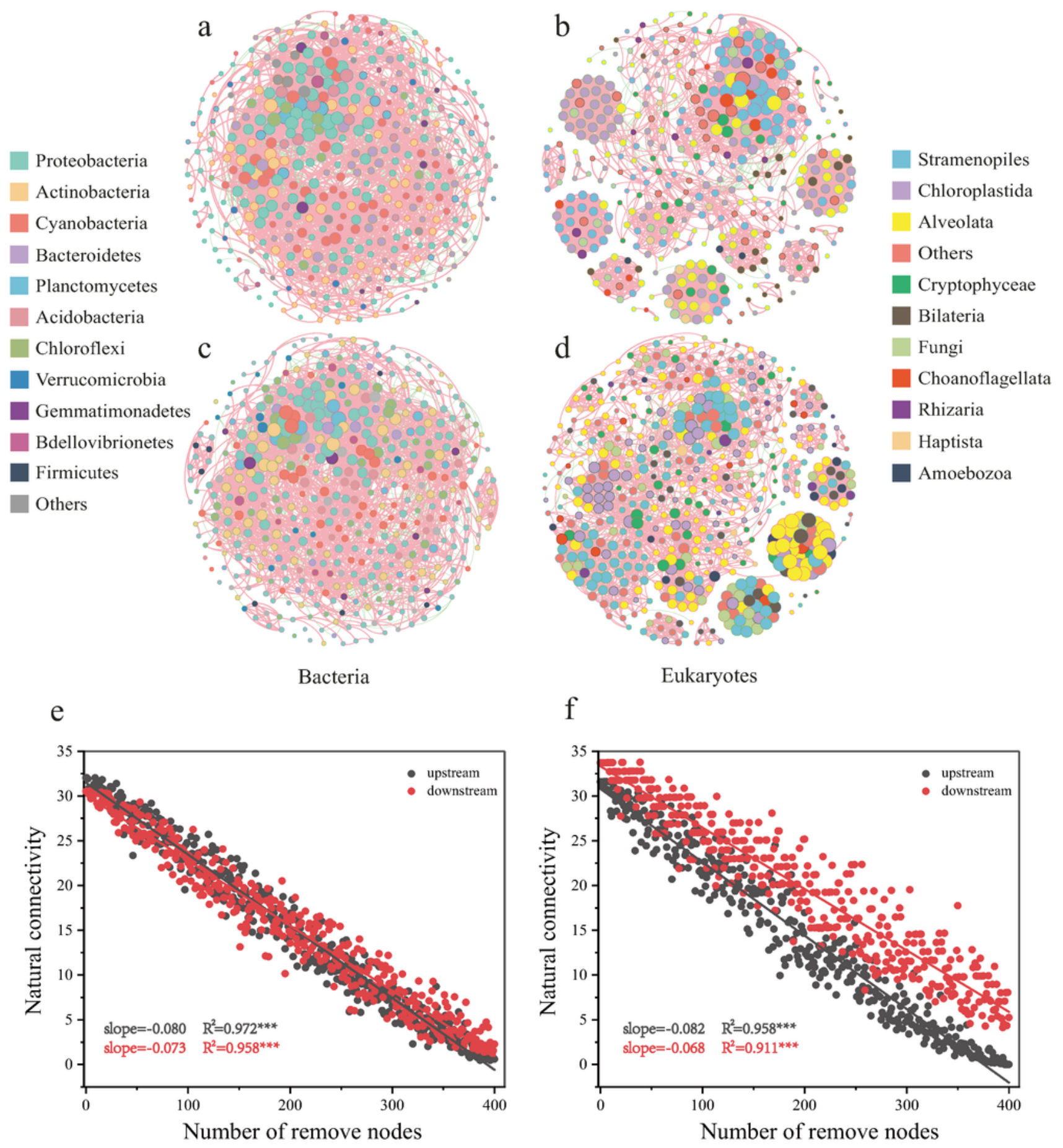

moebozoa

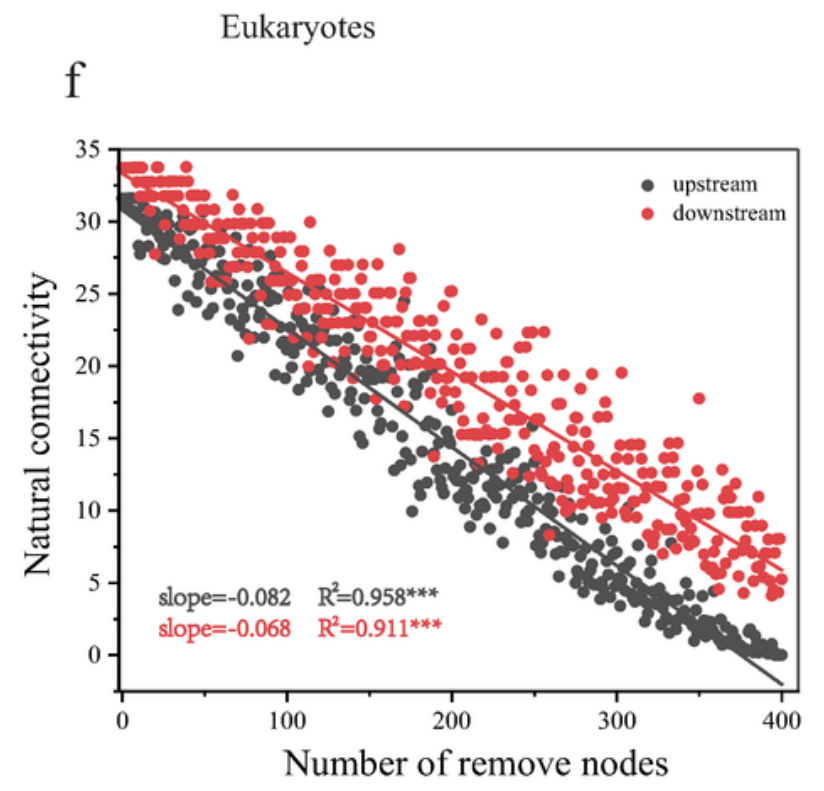

\section{Figure 5}

Co-occurrence networks and robustness analysis of the planktonic bacterial and eukaryotic communities. Planktonic bacterial (a) and eukaryotic (b) co-occurrence networks upstream of the dam; planktonic bacterial (c) and eukaryotic (d) co-occurrence networks downstream of the dam; each node represents an ASV; the nodes are colored based on the different taxonomies; the size of the nodes indicates the abundance of the ASVs; the thickness of the edges indicates the strength of the correlation among the 
ASVs (the pink edges indicate positive correlations among the ASVs, and the green edges indicate negative correlations among the ASVs); changes in the natural connectivity of the planktonic bacterial (e) and eukaryotic (f) co-occurrence networks.

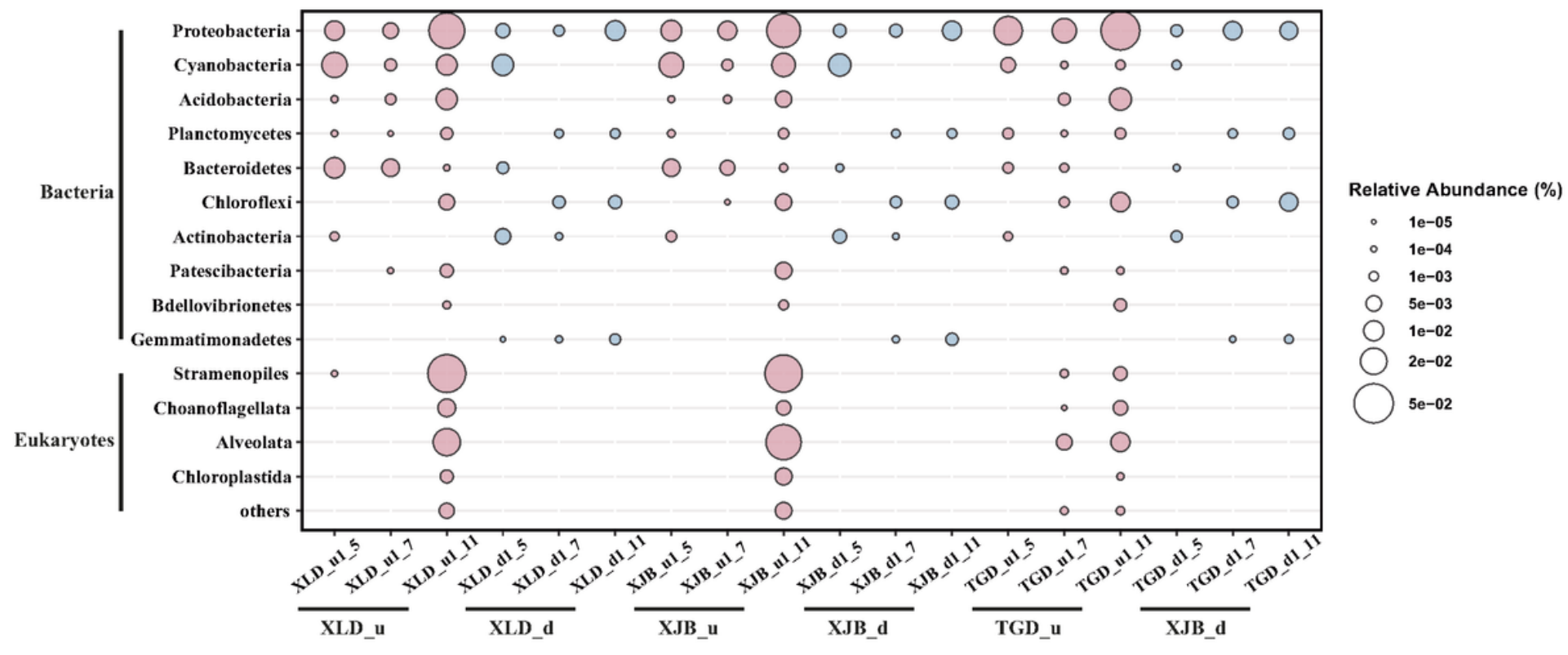

Figure 6

Bubble diagram of the keystone species in the networks upstream and downstream of the dams.

a

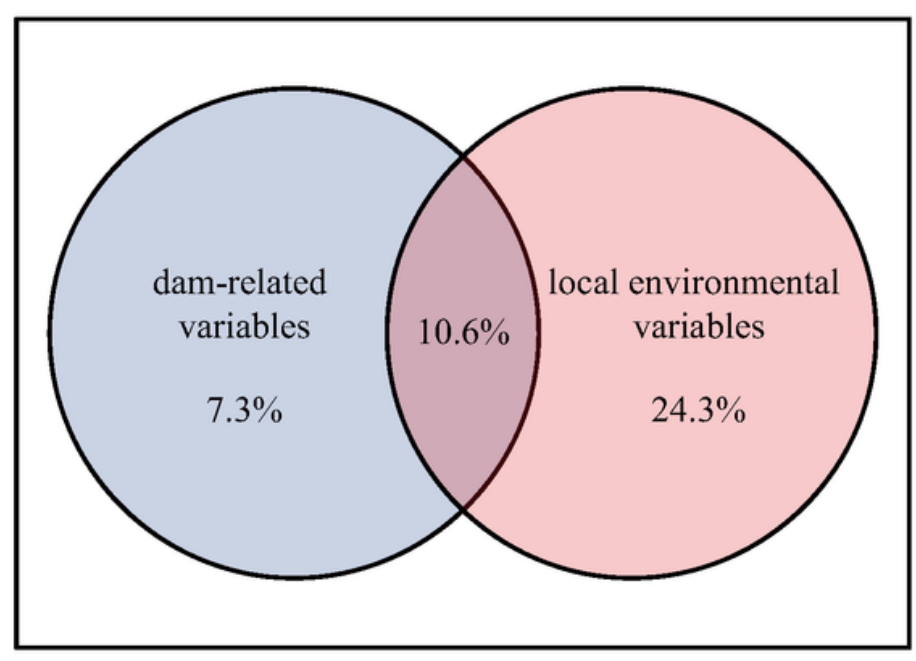

Values $<0$ not shown b Eukaryotes

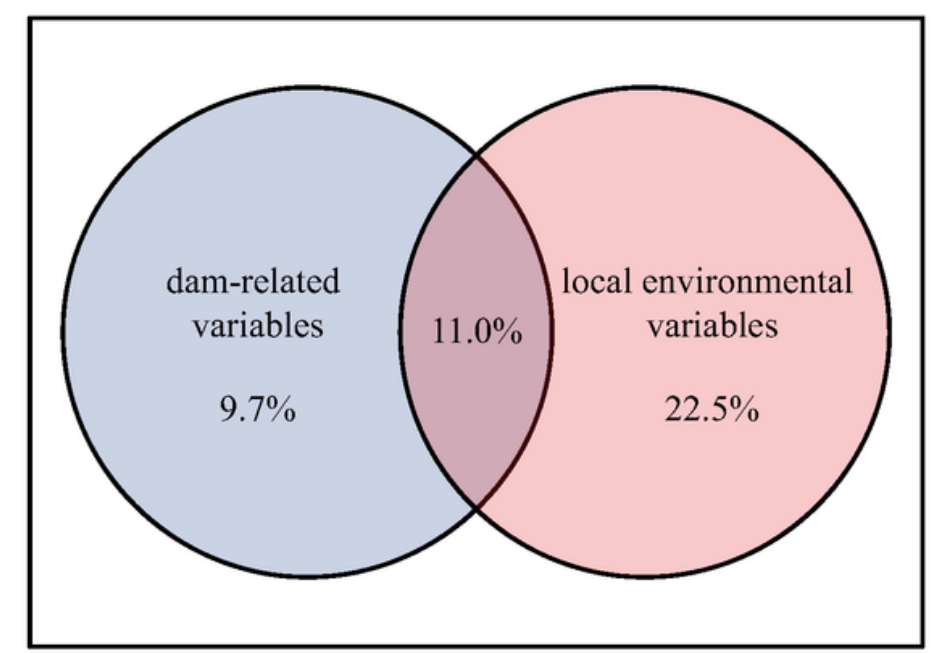

Values $<0$ not shown

\section{Figure 7}

Variation partitioning analysis (VPA) of the planktonic bacterial and eukaryotic communities based on the dam-related variables and local environmental variables.

\section{Supplementary Files}


This is a list of supplementary files associated with this preprint. Click to download.

- SupplementaryMaterial.docx 